\title{
Corrigendum: Virtual Avatar for Emotion Recognition in Patients with Schizophrenia: A Pilot Study
}

\author{
Samuel Marcos-Pablos ${ }^{1 *}$, Emilio González-Pablos ${ }^{2}$, Carlos Martín-Lorenzo ${ }^{2}$, \\ Luis A. Flores ${ }^{2}$, Jaime Gómez-García-Bermejo ${ }^{3}$ and Eduardo Zalama ${ }^{3}$ \\ ${ }^{1}$ Cartif Foundation, Parque Tecnológico de Boecillo, Valladolid, Spain, ${ }^{2}$ Research Unit, Hermanas Hospitalarias Centro \\ Sociosanitario Palencia, Palencia, Spain, ${ }^{3}$ Instituto de Tecnologías Avanzadas de la Producción, Departamento de Ingeniería \\ de Sistemas y Automática, University of Valladolid, Valladolid, Spain
}

Keywords: schizophrenia, facial recognition of emotions, realistic virtual avatar

\section{A corrigendum on}

Virtual Avatar for Emotion Recognition in Patients with Schizophrenia: A Pilot Study by Marcos-Pablos, S., González-Pablos, E., Martín-Lorenzo, C., Flores, L. A., Gómez-García-Bermejo, J., and Zalama, E. (2016). Front. Hum. Neurosci. 10:421. doi: 10.3389/fnhum.2016.00421

\section{OPEN ACCESS}

Edited and reviewed by: Mikhail Lebedev

Duke University, USA

*Correspondence:

Samuel Marcos-Pablos sammar@cartif.es

Received: 09 September 2016 Accepted: 17 October 2016 Published: 02 November 2016

Citation:

Marcos-Pablos S, González-Pablos E, Martín-Lorenzo C, Flores LA,

Gómez-García-Bermejo J and Zalama E (2016) Corrigendum: Virtual Avatar for Emotion Recognition in

Patients with Schizophrenia: A Pilot

Study. Front. Hum. Neurosci. 10:554. doi: 10.3389/fnhum.2016.00554
In the original article, we have neglected to thank our sponsors. The following Funding section should be added:

"This work was supported by the Ministry of Science and Innovation, fundamental research project ref. DPI2014-56500-R and Junta de Castilla y León ref. VA036U14.”

The authors apologize for this oversight. This error does not change the scientific conclusions of the article in any way.

\section{AUTHOR CONTRIBUTIONS}

All authors listed, have made substantial, direct and intellectual contribution to the work, and approved it for publication.

Conflict of Interest Statement: The authors declare that the research was conducted in the absence of any commercial or financial relationships that could be construed as a potential conflict of interest.

Copyright (c) 2016 Marcos-Pablos, González-Pablos, Martín-Lorenzo, Flores, Gómez-García-Bermejo and Zalama. This is an open-access article distributed under the terms of the Creative Commons Attribution License (CC BY). The use, distribution or reproduction in other forums is permitted, provided the original author(s) or licensor are credited and that the original publication in this journal is cited, in accordance with accepted academic practice. No use, distribution or reproduction is permitted which does not comply with these terms. 